\title{
O Paradoxo de Bobbio Pode um Positivista Defender os Direitos Humanos?
}

\section{Victor Sales Pinheiro}

Professor-adjunto da Universidade Federal do Pará (UFPA). Coordenador do Grupo de Pesquisa (CNPq) "Tradição da Lei Natural". Doutor em Filosofia pela Universidade do Estado do Rio de Janeiro (Uerj). Mestre em Filosofia pela Pontifícia Universidade Católica do Rio de Janeiro (PUC-RIO). Graduado em Direito no Centro Universitário do Estado do Pará (Cesupa). vvspinheiro@ yahoo.com.br

\section{Elden Borges Souza}

Mestrando em Direito pelo Programa de Pós-Graduação em Direito (PPGD) da Universidade Federal do Pará (UFPA). Bacharel em Direito pelo Centro Universitário do Estado do Pará (Cesupa). Bolsista da Coordenação de Aperfeiçoamento de Pessoal de Nível Superior (Capes). Pesquisa desenvolvida no Grupo de Pesquisa (CNPq) "Tradição da Lei Natural”. elden.borges@gmail.com

\section{RESUMO}

A luta por direitos humanos tornou-se uma característica dos debates políticos e jurídicos contemporâneos. Direitos, no entanto, não existem sem uma teoria pressuposta. Nesse sentido, o objetivo do presente estudo é analisar na obra de Norberto Bobbio a relação entre a defesa dos direitos humanos e o Positivismo Jurídico. De início, será apresentada sua concepção de uma teoria dos direitos humanos. Em seguida, a sua construção de uma teoria do Direito positivista. Por fim, será 
realizada uma análise crítica dessa relação, para saber se é possível um conceito satisfatório de direitos humanos positivados. Essa análise toma por base os direitos humanos como limites ao poder e, dessa forma, garantia do indivíduo.

Palavras-Chave: Direitos humanos. Positivismo Jurídico. Norberto Bobbio.

\title{
The Paradox of Bobbio: Can a Positivist Defend Human Rights?
}

\begin{abstract}
The struggle for human rights has become a feature of contemporary political and legal discussions. However, there are no rights without a presupposed theory. In this sense, the objective of this study is to analyze on the work of Norberto Bobbio the relationship between the defense of human rights and the Legal Positivism. At first, it will be presented his conception of a theory of human rights. Then, his construction of a theory of Legal Positivism. Finally, a critical analysis of this relationship will be conducted to find out if a satisfactory concept of positivized human rights is possible. This analysis takes a human rights basis as limits to power and thus an individual guarantee.
\end{abstract}

Keywords: Human rights. Legal Positivism. Norberto Bobbio.

Sumário: 1 Introdução. 2 Bobbio, o Defensor dos Direitos Humanos. 3 A Defesa de uma Teoria Positiva do Direito. 4 A Contradição: Do Poder do Estado para o Poder da Comunidade Internacional. 5 Conclusão. 6 Referências. 


\section{INTRODUÇÃO}

Em tempos de incerteza, os arquipélagos de certeza garantem ao homem mais do que segurança e estabilidade. Garantem uma forma de paz. Ainda que houvesse uma convicção inconsciente das enormes violações à vida humana perpetradas pelos regimes autocráticos durante a Segunda Guerra Mundial, um documento que representasse a certeza desse ideal era muito importante.

Com isso em vista, Bobbio desenvolve uma teoria dos direitos humanos baseada na positivação realizada no contexto internacional, principalmente pela Declaração Universal dos Direitos Humanos. Sua posição nesse tema não está, no entanto, dissociada de sua Teoria do Direito. Ao contrário, é uma forma de aplicação de sua concepção de Positivismo Jurídico. Tendo sido historicamente uma afirmação do jusnaturalismo, a defesa dos direitos naturais, direitos do homem ou direitos humanos era um desafio ao Positivismo Jurídico. A proposta de Bobbio é, portanto, estruturar uma teoria desses direitos que se compatibilize com a sua Teoria do Direito em geral.

Nesse sentido, o objetivo do presente texto é analisar a possibilidade de afirmação de uma concepção de direitos humanos dentro de uma visão positivista clássica, ambas a partir dos escritos de Bobbio. Com base na exposição das ideias do autor sobre os direitos humanos e sobre a Teoria do Direito, será realizado um cotejamento crítico. A importância de realizar essa análise a partir das obras de Norberto Bobbio decorre do fato de ele ter uma produção vasta e sistemática sobre os dois assuntos. Em Bobbio, portanto, não é necessária a criação de um diálogo artificial entre autores, pois ele concentra as análises sobre os dois pontos, tanto sobre os direitos humanos quanto sobre o Positivismo Jurídico. 
A partir da apresentação da sua visão sobre os dois temas, a questão posta é se é possível a defesa dos direitos humanos como foi classicamente concebida, inclusive nas declarações de direitos. O Positivismo Jurídico, portanto, defendido por Bobbio, permite uma compreensão dos direitos humanos enquanto limite ao poder do Estado e garantia de uma proteção do ser humano? Para tal objetivo, o trabalho será baseado em uma pesquisa bibliográfica centrada nas principais obras de Bobbio que tratam sobre os direitos humanos e sobre sua Teoria do Direito. De início, será apresentada sua visão dos direitos humanos. Em seguida, a sua construção de uma Teoria do Direito. Por fim, feitas as contextualizações, será realizada uma análise crítica dessa relação.

\section{BOBBIO, O DEFENSOR DOS DIREITOS HUMANOS}

A interligação - proposital ou não - entre política e Direito realizada por Norberto Bobbio pode ser considerada uma das maiores dificuldades para lidar com o seu pensamento. Em algumas questões, como no caso dos direitos humanos, é difícil separar os dois aspectos de sua teoria - que ele trata lado a lado (BOBBIO, 2004, p. 25). Sua ideia precisa ser exposta como defendida e posteriormente analisada em cotejo com sua posição acerca do Positivismo Jurídico. A obra de Bobbio é ampla e diversificada, tratando desde o conceito de norma jurídica (BOBBIO, 2001) e ordenamento jurídico (BOBBIO, 1995b) até a discussão sobre o racismo (BOBBIO, 2002) e a pena de morte (BOBBIO, 2004). Sua defesa dos direitos humanos também é esparsa, porém o núcleo de sua teoria foi estruturado na primeira parte de "A Era dos Direitos" (2004, p. 1).

A defesa dos direitos humanos na obra em questão vai partir de um ponto diferente do utilizado pelo Jusnaturalismo clássico. Toda sua defesa tenta rebater a ideia de direitos dados pela natureza - com um 
fundamento único e absoluto - e busca afirmar um conceito baseado em uma construção jurídica histórica voltada ao aprimoramento da convivência coletiva.

De início, Bobbio (2004, p. 1) defende que o reconhecimento e a efetiva proteção dos direitos humanos não dependem apenas das Constituições dos Estados. O âmbito internacional é essencial à garantia da paz - que, por sua vez, é um pressuposto a esses direitos. E mais, sem a democracia a paz almejada não será alcançada - nem, consequentemente, os direitos humanos. Esse ponto está baseado na ideia de paz perpétua de Kant - uma ideia problemática na atualidade. Segundo Kant (2002, p. 119-171), a história da humanidade seguiria um progresso - determinado pela natureza - de uma condição de guerra entre os homens e os povos até a formação de uma federação universal cosmopolita, que asseguraria a paz perpétua - e, em decorrência, a liberdade -, em razão dos limites internos e externos aos Estados.

Assentada a importância do tema, Bobbio passa a analisar o conceito de direitos humanos - ao mesmo tempo em que procura hastear a bandeira de sua efetivação. Em síntese, seu argumento volta-se à questão do fundamento, da origem e do desenvolvimento desses direitos. Bobbio (2004, p. 9) introduz a obra expondo como a linguagem dos direitos humanos é frequentemente utilizada de modo retórico. Normalmente se atribui a expressão "direitos" a aspirações ideais, como forma de atribuir um título de nobreza - que não é desfrutado na prática. E entre os diversos pontos de vista acerca da fundamentação dos direitos humanos, o argumento de Bobbio foi muito difundido. Sua posição é de que os direitos humanos são históricos, o que afeta não apenas a legitimidade, mas também a eficácia da busca por um fundamento absoluto (BOBBIO, 2004, p. 2).

Nesse sentido, partindo da noção de que estes direitos são desejáveis, o autor deixa claro que a busca por um fundamento tem por objetivo motivar seu amplo reconhecimento. Essa finalidade levaria a uma ilusão 
acerca da existência de um fundamento absoluto - e, portanto, irresistível, capaz de assegurar o reconhecimento de todos os direitos humanos (2004, p. 15-16). Essa é a base para a sua crítica ao Jusnaturalismo - que deriva tais direitos da natureza humana. Sua percepção é que os conceitos de "natureza" e "direitos do homem" são extremamente frágeis e não permitem tal conclusão. O Jusnaturalismo, para Bobbio, somente assegura uma ideia genérica, a partir da qual cada autor defende determinados direitos em detrimento de outros, conforme uma particular noção de natureza humana (2004, p. 16-17).

Em primeiro lugar, os conceitos desses direitos seriam tautológicos e conforme a ideologia do intérprete - baseados em fórmulas vagas, incapazes de solucionar contradições. Bobbio (2004, p. 18) volta-se contra esses fundamentos - reflexos de "valores últimos" - a partir de um ceticismo de que tais valores se justifiquem ou mesmo que sejam objetivamente conciliáveis.

Além disso, esses direitos são histórica e culturalmente variados - provando a inexistência de uma fundamentação com base na natureza. Bobbio (2004, p. 5-6) identifica estes direitos como frutos de "lutas em defesa de novas liberdades contra velhos poderes", gerando um nascimento gradual - não completo e não definitivo. Seu nascimento ocorre dentro de circunstâncias: quer pela necessidade de novas liberdades, quer pela capacidade de assegurar novos remédios contra indigências.

Em terceiro lugar, Bobbio (2004, p. 19-20) não considera plausível um fundamento único em razão da heterogeneidade dos direitos humanos. Muitos deles seriam diferentes e até mesmo antagônicos - fazendo com que a afirmação de um novo direito leve à supressão de um direito anterior. Logo, não haveria porque se falar em um único fundamento, e sim em uma pluralidade de fundamentos, conforme os direitos que se queira defender. 
Disso, conclui que a contradição é o principal opositor à busca por um fundamento absoluto (BOBBIO, 2004, p. 21). Os direitos consagrados na contemporaneidade seriam antinômicos, a realização integral de uns exclui a de outros. Um fundamento absoluto não permitiria a defesa de um direito e, ao mesmo tempo, de seu oposto. Em consequência, Bobbio inclusive considera tal ideia prejudicial ao avanço no reconhecimento de direitos. "O fundamento absoluto não é apenas uma ilusão; em alguns casos, é também um pretexto para defender posições conservadoras” (BOBBIO, 2004, p. 22). Ou seja, um suposto fundamento poderia dificultar o avanço na positivação desses ideais.

Um último aspecto da análise de Bobbio (2004, p. 22) sobre a fundamentação consiste em sua crítica à demonstrabilidade dos valores últimos. Ele rejeita que a demonstração racional de um valor seja condição necessária e suficiente para os direitos humanos. Sua crítica está centrada na realização concreta desses direitos. Enquanto na época da defesa de um fundamento absoluto os direitos humanos não eram mais respeitados, na atualidade que questiona esse fundamento foi proclamada a Declaração Universal dos Direitos Humanos (BOBBIO, 2004, p. 22).

A partir disso, ele adota uma visão consensual dos direitos humanos, em que a convicção partilhada universalmente entre os povos - cristalizada em documentos internacionais, como a Declaração Universal - supre a busca por um fundamento (2004, p. 23). Ainda que o convencimento acerca da bondade desses direitos seja importante, o essencial para sua realização é a criação das condições reais para sua instituição.

Prossegue: "O problema fundamental em relação aos direitos do homem, hoje, não é tanto o de justificá-los, mas o de protegê-los. Trata-se de um problema não filosófico, mas político” (BOBBIO, 2004, p. 23, grifos no original). O problema filosófico teria sido resolvido por um consenso 
geral único operado por meio da Declaração Universal de 1948 - uma vez que nem a dedução da natureza humana, nem a defesa da autoevidência lograram êxito (2004, p. 26).

O que está subjacente a esta rejeição pela busca de um fundamento é a hipótese - também baseada no pensamento de Kant (2002) - de um suposto progresso moral da humanidade, do qual a positivação dos direitos humanos seria o maior exemplo (2004, p. 47-49). O pensamento de Bobbio compreende a História como uma reta contínua e ascendente, na qual os direitos humanos estariam próximo ao ápice.

Como consequência da simultânea rejeição a um fundamento absoluto e, por outro lado, defesa de um progresso moral da sociedade, Bobbio (2004, p. 27-28) caracteriza os direitos humanos como históricos, heterogêneos - exigindo ora abstenção, ora intervenção estatal - e não absolutos, como decorrentes de uma escolha subjetiva recente e não como algo objetivamente dado. Somente podem ser absolutos na hipótese excepcional de não existir um direito concorrente (2004, p. 41). Seriam, portanto, direitos mutáveis e suscetíveis de transformação e ampliação (p. 32).

Sob o prisma da origem e do desenvolvimento, Bobbio (2004, p. 28-29) considera o Jusnaturalismo de Locke como precursor filosófico das declarações de direitos. A partir das teorias, os primeiros legisladores - de alguns Estados - passam a acolher determinados direitos, como na Declaração Francesa de 1789. No primeiro momento teria ocorrido a conversão das doutrinas jusnaturalistas em Direito Positivo (BOBBIO, 2004, p. 47).

Esse desenvolvimento, baseado em uma crescente consciência moral do sofrimento do homem no mundo e de sua igualdade, decorreu da mudança de uma concepção organicista para uma concepção individualista - em que o indivíduo, que possui valor em si mesmo, antecede ao Estado. Como consequência, a função estatal é a plena realização do indivíduo, de forma geral (2004, p. 56-57). 
Em 1948, com a Organização das Nações Unidas, esses direitos passaram a ser concomitantemente gerais (ou universais) e positivos. A partir de então eles valem até mesmo contra os Estados (BOBBIO, 2004, p. 29-30). Em que pese sua importância, esse processo não se encerrou nessa fase. Os direitos humanos permanecem sendo um meio de induzir mudança social, que produz um constante aprimoramento da sociedade.

Em razão disso, a proteção internacional genérica - isto é, independente de especificidades dos indivíduos - deu espaço a um processo de especificação. De um titular abstrato, passou-se a um ser humano com gênero, fase da vida e condição especial (BOBBIO, 2004, p. 58-59), e esse processo permanece aberto conforme as pretensões aumentam. Esse aumento de necessidades levou também à ampliação dos bens e dos sujeitos tutelados, com o reconhecimento de novos direitos (BOBBIO, 2004, p. 63). Trata-se de um fenômeno de multiplicação de direitos, derivado principalmente da crescente complexidade das relações sociais, refletido nas declarações internacionais de direitos (p. 69).

Apesar dos avanços, persistem algumas dificuldades - além da mais comum, que é a de efetivação - no âmbito internacional, uma vez que somente os Estados possuem poder de coerção, enquanto os demais entes internacionais têm somente capacidade de promoção. Para que a tutela internacional funcionasse adequadamente uma parte deveria possuir autoridade e a outra disposição a aceitar as recomendações - e às vezes faltam as duas condições (BOBBIO, 2004, p. 37).

Em razão disso, em âmbito internacional não haveria uma proteção jurídica em sentido estrito, tendo em vista que os organismos internacionais não possuem poder, e sim somente influência (de promoção, controle e garantia). As garantias internacionais estariam, portanto, em fase de evolução (BOBBIO, 2004, p. 39-40) - cuja esperança está no progresso 
da humanidade. Nesse sentido, é preciso registrar que as missões de paz conduzidas pela ONU e as manifestações do Conselho de Segurança estão caminhando nessa direção.

A compreensão de direitos humanos em Bobbio depende, como se vê, de sua compreensão da Teoria do Direito.

\section{A DEFESA DE UMA TEORIA POSITIVA DO DIREITO}

Além de teórico político (e político) e árduo defensor dos direitos humanos, os escritos de Bobbio também ganharam relevância na Teoria do Direito. Podem ser destacados O Positivismo Jurídico (BOBBIO, 1995a), Teoria da norma jurídica (BOBBIO, 2001) e "Teoria do ordenamento jurídico" (BOBBIO, 1995b). Embora após Kelsen (2009) a visão do Positivismo Jurídico tenha sido aprimorada - por Hart (2009), principalmente -, em razão do período em que escreveu, Bobbio sempre parte desta primeira visão teórica. Assim, sua posição positivista pode ser considerada clássica.

Em primeiro lugar, deve ser observado que Bobbio (1995b, p. 19) compreende o Direito sob o aspecto formal, não somente a partir da compreensão da norma jurídica, mas também - e principalmente - a partir da relação entre as normas, isto é, a partir da compreensão do ordenamento jurídico. Essa é a sua diferença inicial para Kelsen, que isolou os problemas das normas dos problemas do ordenamento, dando um tratamento autônomo a este.

Na sua definição da norma jurídica, Bobbio (2001, p. 145) esforça-se, principalmente, para diferenciar as diversas espécies de normas existentes, para encontrar o conceito da norma jurídica. Para tanto, destaca que não se trata de uma característica puramente formal, como a linguagem prescritiva. Para Bobbio (2001, p. 147-148), não é suficiente a distinção com base em um critério material, como as ideias de relação 
intersubjetiva ou de finalidade. A proposta do Positivismo Jurídico é definir como jurídica uma norma conforme o sujeito que a estabeleceu (BOBBIO, 2001, p. 149).

O critério do sujeito define a norma jurídica independentemente da forma que assume ou do fim a que se propõe. Considera-se jurídica a norma posta pelo poder soberano. E "poder soberano" é aquele acima do qual não existe nenhum outro - considerando determinado grupo social - e em posição de dominar todos os outros (BOBBIO, 2001, p. 149). As normas jurídicas tornam-se normas essenciais, pois o poder soberano detém o monopólio da força e, por consequência, a capacidade de fazê-las valer. Assim, sua execução é garantida por uma sanção externa e institucionalizada - o que já remete a um completo sistema normativo (2001, p. 150).

Destarte, a definição de Direito depende de um complexo de normas, não é possível exclusivamente a partir da norma jurídica tomada de forma isolada. O problema dessa relação é essencial para Bobbio (1995b, p. 21-22), pois a norma precisa ter eficácia - aliás, isso fica claro em sua defesa dos direitos humanos -, e essa eficácia depende do conjunto de normas.

Ao mesmo tempo em que a norma jurídica e, consequentemente, o ordenamento jurídico são definidos por meio da soberania, é também verdade que a soberania em uma determinada sociedade se define mediante o ordenamento jurídico. Por isso, o que vem em primeiro lugar é o ordenamento e não a norma isolada (BOBBIO, 1995b, p. 25-26). "A soberania caracteriza não uma norma, mas um ordenamento; caracteriza a norma apenas quando ela é considerada como parte do ordenamento" (1995b, p. 26).

Assim, o problema de definir o Direito é uma questão de definir o ordenamento normativo - norma jurídica é aquela que pertence a este sistema. Dessa forma, a sanção organizada não se refere à norma, e sim 
ao ordenamento normativo (BOBBIO, 1995b, p. 28-29). Esse ordenamento é caracterizado por uma pluralidade de normas jurídicas, pois ao lado das normas de conduta existem as de estrutura ou de competência, as quais fixam "as condições e os procedimentos através dos quais emanam normas de conduta válidas” (1995b, p. 33).

Como positivista, Bobbio estrutura o conceito de ordenamento jurídico a partir das ideias de unidade, sistema e completude. Dedica-se, portanto, a afastar problemas hierárquicos, de antinomia e de lacunas. Mesmo as dificuldades decorrentes da diversidade de ordenamentos encontram soluções (formais) em seu entendimento - o que asseguraria segurança jurídica (BOBBIO, 1995b, p. 34-35).

A solução, no entanto, para todos os problemas identificados, ao final encontra a mesma resposta: a soberania estatal. Sobre a pedra fundamental do Estado está assentada a unidade, a sistematicidade e a completude do ordenamento jurídico. Todas as normas, mesmo as particulares, retiram sua validade - no caso, por delegação (BOBBIO, 1995b, p. 38) - do Estado-Soberano, que se caracteriza como a fonte das fontes (1995b, p. 41).

Outra característica do modelo de ordenamento de Bobbio é que, além de regular o comportamento das pessoas, ele também estabelece o modo pelo qual se devem produzir as normas. E a presença e a frequência dessas normas de estrutura - que regulamentam o modo de regular um comportamento - definem a complexidade do ordenamento jurídico (BOBBIO, 1995b, p. 45-47).

Por consequência, a unidade do ordenamento depende de uma norma fundamental - que autoriza todas as demais. Afinal, toda norma pressupõe um (e deriva de um) poder normativo - no caso da Constituição é o poder constituinte. Por outro lado, todo poder normativo pressupõe uma norma que o autoriza a produzir normas jurídicas. Logo, no caso do poder constituinte essa norma pressuposta é a norma fundamental (1995b, p. 58). 
A norma fundamental, ao lado do poder constituinte, "impõe a todos aqueles aos quais se referem as normas constitucionais o dever de obedecê-las" (1995b, p. 59). Essa norma fundamental não é expressa e sim pressuposta - para fundar e dar unidade ao sistema normativo. É o ponto de apoio do sistema, caracterizando o poder constituinte como poder jurídico, e “o fato de essa norma não ser expressa não significa que não exista” (BOBBIO, 1995b, p. 60). A norma fundamental funciona como fundamento último, pois a validade de uma norma em relação ao ordenamento depende do poder legítimo de estabelecer normas jurídicas - que, ao final, reside nela.

Baseando-se em Kelsen, Bobbio (1995b, p. 62) vincula a própria existência de um ordenamento à norma fundamental: “[...] a norma fundamental é o critério supremo que permite estabelecer se uma norma pertence a um ordenamento; em outras palavras, é o fundamento de validade de todas as normas do sistema”. A preocupação positivista de defender uma norma pressuposta - que não é expressa - é a preocupação de afastar a ideia de que o Direito seja fruto unicamente da força. Afinal, sem qualquer baliza material, o que restaria ao Positivismo seria reconhecer que o mais forte decide o que é jurídico ou não. A ideia de uma norma fundamental poderia afastar essa conclusão, mas na prática essa norma não garante qualquer materialidade ao Direito subsequente.

Bobbio (1995b, p. 70), então, defende que a força não é o objeto do Direito - ou seja, aquilo que deveria ser controlado - e sim o seu instrumento -, o meio por ele operado para alcançar determinados fins. $\mathrm{O}$ objeto do Direito seria organizar a sociedade por intermédio da força. Isso se compatibiliza com a sua visão de direitos humanos, pois a força é essencial à eficácia - e esta, como dito, essencial à caracterização do jurídico e do não jurídico. Essa eficácia, no entanto, não tem qualquer baliza dada pela norma fundamental. Como consequência, o Direito pode ser definido independentemente de qualquer critério de justiça: 
A definição do Direito, que aqui adotamos, não coincide com a de Justiça. A norma fundamental está na base do Direito como ele é (o Direito positivo), não do Direito como deveria ser (o Direito justo). Ela autoriza aqueles que detêm o poder a exercer a força, mas não diz que o uso da força seja justo só pelo fato de ser vontade do poder originário. Ela dá uma legitimação jurídica, não moral, do poder. $\mathrm{O}$ Direito, como ele é, é expressão dos mais fortes, não dos mais justos (BOBBIO, 1995b, p. 67).

Quando analisou o critério da justiça na definição da norma jurídica, Bobbio (2001, p. 150) rejeitou a possibilidade por uma possível vagueza. Aliás, esse critério valorativo no Direito ele considera extremamente problemático, impedindo a caracterização do jurídico - em distinção à ordem moral, por exemplo.

A preocupação de Bobbio é a mesma de Kelsen, de tornar o Direito uma ciência, utilizando-se dos padrões dados pelas Ciências Naturais. Kelsen (2009, p. 85) deixa claro seu objetivo de sempre tentar comparar as Ciências Sociais às Ciências Naturais, buscando objetividade e, consequentemente, cientificidade. O mesmo ideal de objetividade move Bobbio, que tenta apresentar uma Teoria Positiva do Direito. Seus conceitos de norma e de ordenamento vinculam-se sempre à soberania, pois sua visão do Direito quer afastar-se de valores. Em sua visão o Direito é um fato e não um valor, o que permite que o jurista estude o Direito como um cientista estuda a realidade natural (BOBBIO, 1995a, p. 131).

Como "o Direito é tal que prescinde do fato de ser bom ou mau, de ser um valor ou um desvalor” (BOBBIO, 1995a, p. 131), a sua validade está fundada em critérios que concernem unicamente à sua estrutura formal. Por outro lado, a definição do Direito está associada à coação (1995a, p. 158) - o que devolve sua afirmação ao poder do Estado. Em uma simplificação talvez excessiva, o Direito em Bobbio importa-se com a regulação 
da conduta, o que ocorrerá por meio de normas que definirão quem deve usar a força; quando a força pode ser acionada; como deve ser exercida e em que medida deve ser aplicada (p. 158).

A principal consequência é que a legitimidade do Direito é estritamente formal, não dependendo do conteúdo das normas ou do sentido do ordenamento. Aquilo que, dado pelo poder soberano, for criado nestes moldes será jurídico - o restante é expulso para o campo da especulação, ou do mero desejável. Em grande medida, como pode ser observado, esta compreensão não contradiz o pensamento de Bobbio sobre os direitos humanos. A questão, no entanto, é se essa visão é suficiente para aquilo a que esses direitos se propuseram.

\section{A CONTRADIÇÃO: DO PODER DO ESTADO PARA O PODER DA COMUNIDADE INTERNACIONAL}

Após a exposição paralela da visão de Bobbio sobre os direitos humanos e sobre a Teoria do Direito é possível perceber diversas contradições com aquilo a que os primeiros se propuseram: uma luta contra a opressão estatal e uma garantia jurídica do indivíduo não criada pelo poder do legislador.

De início, a primeira consideração diz respeito à desnecessidade da busca por uma fundamentação. Dentro de uma ótica positivista, pautada essencialmente na formalidade, os documentos internacionais podem suprir uma discussão - o que em si é contraditório, como será demonstrado - por fundamentos. Como defende Robles (2005, p. 1-4), no entanto, essa ideia de Bobbio conjuga dois problemas distintos, um prático (ou político) e outro teórico (ou filosófico). As dificuldades postas por Bobbio podem ser reconhecidas, sem que isso inviabilize a necessidade de discussão sobre o conceito - que tem, necessariamente, um fundamento - de direitos humanos. 
Os documentos internacionais gerais - como a Declaração Universal dos Direitos Humanos, no âmbito da Organização das Nações Unidas (ONU), o Pacto de São José da Costa Rica, no âmbito da Organização dos Estados Americanos (OEA), a Convenção Europeia de Direitos Humanos, na União Europeia, e a Carta Africana dos Direitos dos Homens e dos Povos, na União Africana - são a consolidação de um processo político de afirmação dos direitos humanos. Da mesma forma, os diversos relatórios específicos produzidos por organismos internacionais e por Organizações Não Governamentais (ONGs) comprovam que as violações aos direitos humanos são comuns e constantes. Esses documentos lembram que uma missão foi assumida pelos mais diversos países e que esse dever ainda não foi devidamente cumprido. O quadro político, realmente, não dá uma grande margem para questionar se esses direitos devem ou não ser realizados. Eles precisam ser, mas isso não exclui a necessidade de fundamentá-los.

Robles (2005, p. 1-2) elenca quatro razões para buscar esse fundamento. Em primeiro lugar, é absurdo defender um valor sem saber o motivo. Em segundo lugar, um fundamento delimita um conteúdo concreto ao que se denomina “direitos humanos”. Em terceiro lugar, não é possível apresentar uma teoria sobre os direitos humanos sem fundamentá-los. Por fim, para a efetivação de direitos é indispensável a existência de ideias claras.

Como fica claro, esse problema somente existe se for reconhecida a insuficiência do Positivismo Jurídico defendido por Bobbio para justificar adequadamente os direitos humanos. E essa insuficiência depende do reconhecimento de que esses direitos merecem uma posição de destaque não em razão da autoridade da qual emanou - quer a Assembleia Constituinte, quer a Assembleia Geral da ONU -, e sim por causa do valor que representa. 
Da necessidade de fundamentação também se conclui que nem tudo pode ser denominado “direitos humanos”. Da exposição de Bobbio qualquer pretensão amplamente aceita - vulgarmente "popular” - e defendida, uma vez positivada pode ser considerada essa espécie de direito. Em essência, não se pode extrair da obra de Bobbio uma distinção entre os direitos em geral e os direitos humanos.

Além disso, aplicando uma ideia de Mill (2011, p. 70), a aceitação dos direitos humanos como um produto simples da legislação (ainda que internacional), relegando a fundamentação a um plano secundário, acabará por prejudicar sua efetivação. Isso, pois sem a discussão sobre o fundamento desses direitos todas as conquistas tornam-se dogmas. A defesa dos direitos humanos não passará de uma confissão de fé, sem poder sobre a conduta. Consequentemente, toda a importância dada pelos argumentos acaba por ser perder com o tempo - o que inevitavelmente irá refletir sobre a prática dos Estados, das instituições e das pessoas.

Pois bem. A questão que se coloca é se esse pensamento positivista - que sustenta a ideia de que os direitos humanos legitimam-se independentemente de fundamentos - é suficiente para a defesa desses direitos. Em outras palavras, a discussão delimita-se em Bobbio, mas acaba por transcendê-lo: Pode um positivista como Bobbio defender os direitos humanos?

O principal contrassenso na obra de Bobbio é que, ao mesmo tempo que defende os direitos humanos como fruto da inversão na relação indivíduo-sociedade, condiciona esses direitos ao reconhecimento pelo Estado ou pela comunidade internacional. A definição do que são direitos humanos, portanto, está sujeita à decisão de um corpo político.

Para este autor (BOBBIO, 2004, p. 4), em uma concepção orgânica tradicional a sociedade é anterior aos indivíduos. Como consequência, o foco está sobre os deveres e não sobre os direitos. Igualmente, no organicismo a lógica do poder não parte do povo, e sim do príncipe. Os direitos 
humanos inverteram essa lógica, dando ênfase ao indivíduo e colocando o foco nos direitos. Consequentemente, a legitimidade do poder, igualmente, voltou seu fundamento ao povo.

O paradoxo é autoevidente quando percebemos que no Positivismo Jurídico defendido por Bobbio nada resta ao indivíduo sem o Estado ou sem a comunidade internacional. De forma involuntária e inevitável, Bobbio retorna ao seu ponto de partida: sem a comunidade o indivíduo não tem mais do que meros desejos e pretensões sem eficácia - pois esta depende do poder institucionalizado. Nesse sentido, interessante observar o ceticismo de Bobbio (2004) em relação a qualquer direito inerente ao homem ou que possa existir antes e independente de qualquer benevolência do Estado - noção essa que foi o germe histórico do conceito de direitos humanos:

Falar de direitos naturais ou fundamentais, inalienáveis ou invioláveis, é usar fórmulas de uma linguagem persuasiva, que podem ter uma função prática num documento político, a de dar maior força à exigência, mas não têm nenhum valor teórico, sendo portanto completamente irrelevantes numa discussão de teoria do direito (p. 6).

Para Bobbio (2004, p. 17), nem a liberdade - o direito básico defendido por Kant - pode ser considerado direito absoluto. Essa conclusão parte de uma premissa positivista de que todos os direitos criados pelo legislador possuem o mesmo fundamento de validade: o poder soberano. Ora, se o fundamento da liberdade e dos demais direitos é a norma positiva - quer de um Estado, quer em âmbito internacional -, não há motivo para definir um deles como mais fundamental.

Ao mesmo tempo, contudo, em que rejeita a ideia de direitos absolutos - pois não podem decorrer do ordenamento posto -, ele lista, exemplificativamente, os direitos a não ser escravizado e a não sofrer tortura 
como absolutos (BOBBIO, 2004, p. 20). Bobbio novamente conduz a uma conclusão paradoxal: Como existe um direito absoluto sem um fundamento absoluto?

Prosseguindo em sua concepção positivista Bobbio assume que se um direito não é afirmado pela legislação e, simultaneamente, dotado de efetiva aplicação, não passa de mera obrigação moral ou, no máximo, política. Normas programáticas e de Direito Internacional fugiriam a um conceito propriamente jurídico (BOBBIO, 2004, p. 72). Outra contradição, considerando que o consenso geral sobre os direitos humanos ocorreu em âmbito internacional.

Em tal situação, sem positivação plena (legislada e efetivada), os direitos humanos seriam uma carta de intenções, sustentada unicamente pela opinião pública (BOBBIO, 2004, p. 72-73). Na prática, a ideia de Bobbio (2004, p. 72) reduz os direitos humanos a um instrumento de retórica internacional ou nacional:

Partilho a preocupação dos que pensam que chamar de "direitos" exigências (na melhor das hipóteses) de direitos futuros significa criar expectativas, que podem não ser jamais satisfeitas, em todos os que usam a palavra "direito" segundo a linguagem corrente, ou seja, no significado de expectativas que podem ser satisfeitas porque são protegidas.

Por prudência, sempre usei, no transcorrer desta minha comunicação, a palavra "exigências" em vez de "direitos", sempre que me referi a direitos não constitucionalizados, ou seja, a meras aspirações, ainda que justificadas com argumentos plausíveis, no sentido de direitos (positivos) futuros.

Quando Bobbio (2004, p. 74) define os direitos humanos como exigências de positivação de determinadas pretensões em um ordenamento, está novamente a reduzir esses direitos à vontade do Estado - pois nem a comunidade internacional possui autoridade para protegê-los de forma efi- 
ciente. Não passam de um conjunto de argumentos, que se não positivados e aceitos pelo poder estatal interessam somente a teóricos. Sua posição, portanto, desloca os direitos humanos do jurídico para o exclusivamente político. Afinal, sem o reconhecimento pelo poder do Estado a discussão não é jurídica, e sim sobre pautas políticas - não vinculantes - para o funcionamento das instituições públicas. Sem essa decisão estatal nada existe:

Uma coisa é ter um direito que é, enquanto reconhecido e protegido; outra é ter um direito que deve ser, mas que, para ser, ou para que passe do dever ser ao ser, precisa transformar-se, de objeto de discussão de uma assembléia de especialistas, em objeto de decisão de um órgão legislativo dotado de poder de coerção (BOBBIO, 2004, p. 77).

Como consequência, os direitos humanos seriam uma semente que apenas cresce no fértil solo do Estado de Direito. Somente em um Estado comprometido com a observância das normas (tanto internas quanto internacionais) e que possui uma estrutura capaz de efetivá-los (ao menos progressivamente) podem ser reconhecidos direitos humanos. Mal comparando, é como a Teoria da Justiça de Rawls (2008, p. 560), que somente é aplicável em uma sociedade bem-ordenada.

Tal argumentação leva Bobbio (2004, p. 40) a outro paradoxo. Quem mais necessita da proteção dos direitos humanos ante o poder público é o povo de um Estado de não Direito, no entanto são exatamente esses que se recusam a aceitar limites ao seu poder. E mais, são esses Estados que rejeitam as normas internacionais. Aí resta esgotado o Positivismo.

Existe, porém, uma questão ainda mais profunda decorrente da característica histórica que não foi respondida: e se a luta por esses direitos não for vitoriosa circunstancialmente, as pretensões de direitos nada significaram? Antes do início da Segunda Guerra Mundial a proibição da tortura, dos tratamentos cruéis e do genocídio era despida de caráter jurídico? Antes do reconhecimento pleno dos direitos civis dos negros americanos não existiam direitos? 
Na prática Bobbio apenas substitui a instância de poder que irá dizer o que é e o que não é um direito humano. Ele repassou do Estado para o âmbito internacional definir esses direitos, mas mesmo assim deixou esse conceito completamente submetido à vontade de um corpo de legisladores. Novamente os direitos humanos são uma concessão do poder, não existindo nada no indivíduo em si que possa protegê-lo contra ambos.

Essa substituição ele precisa reconhecer como inadequada, pois em sua visão a comunidade internacional é incapaz de garantir efetivamente tais direitos. Se em âmbito interno os direitos humanos dependem da existência de um Estado de Direito, eles são completamente inúteis. Se em âmbito internacional os direitos humanos não possuem mecanismos de proteção, eles não têm eficácia. Nos dois casos falar desses direitos não é falar de um conceito jurídico relevante.

O problema dessa visão positivista do Direito é que ao tratar os direitos humanos afastados de uma noção de lei natural (em diferenciação à Lei Positiva) acaba por negar a possibilidade de rejeição a um sistema normativo que não os reconheça (NINO, 2011, p. 27). Como consequência, eles não servem para impugnar juridicamente um ordenamento positivado - a menos que também sejam positivados, o que é paradoxal.

E ainda que seja admitido que a positivação internacional é suficiente, essa ideia continua reduzindo os direitos humanos a um ato de vontade ou de desejo da reunião de Estados. Não existe essa coisa chamada "comunidade internacional" de uma maneira transcendente e que consolida as melhores ideias de justo, bem e paz. O que existe é a reunião de Estados soberanos em organismos internacionais.

O condicionamento do reconhecimento de direitos humanos à aprovação de documentos internacionais é reconhecer que uma votação - que pode ser marcada por fatores contingentes - tem a capacidade de dizer quais são os direitos mais básicos do ser humano. São os próprios 
Estados decidindo voto a voto o que irão aceitar como limites ao seu poder e como compreendem a dignidade humana. A busca por um fundamento é a procura por algo além da Lei Positiva que justifique a defesa desses direitos. É a busca por uma base sólida que proteja o homem contra mudanças eventuais no consenso. Afinal, se o consenso deixar de existir esses direitos também perderão sua validade?

Embora Bobbio trate o jusnaturalismo como mero precedente histórico das declarações de direitos, na verdade essa base buscava exatamente quebrar a submissão integral do Direito às decisões dos Estados. Por isso o preâmbulo da Declaração Universal dos Direitos Humanos faz referência à "dignidade inerente" e à possibilidade de "revolta contra a tirania e a opressão”. Jacques Maritain (1966, p. 83), que participou da comissão de elaboração da Declaração Universal, é enfático ao rejeitar a defesa dos direitos humanos por uma ótica positivista:

O fundamento filosófico dos Direitos do Homem é a Lei Natural. Lamento não podermos encontrar outra palavra! [...]. Eles [os críticos] deveriam, entretanto, lembrar-se de que a história dos direitos do homem está ligada à história da Lei Natural, e que o descrédito em que, por certo tempo, o positivismo lançou a ideia da Lei Natural, provocou inevitavelmente um descrédito semelhante para a ideia dos direitos do homem.

Nesse sentido, Strauss (2014, p. 3) explica que o Positivismo reduz o Direito às decisões dos legisladores e dos tribunais. Logo, seria a manifestação de determinadas preferências, o que acarreta a permissibilidade de qualquer ato (STRAUSS, 2014, p. 6). Somente o que o Estado (ou a ONU) disser - e tudo aquilo que eles disserem - que é direito humano será efetivamente direito. Por isso, a conjugação das posições de Bobbio acerca dos direitos humanos e de uma Teoria Positiva do Direito conduz a 
diversos problemas e, ao fim, à inutilidade jurídica daqueles direitos. $\mathrm{O}$ ser humano novamente se vê dependente da benevolência - não mais somente do Estado, mas também da comunidade internacional.

\section{CONCLUSÃO}

Com base na profícua obra de Norberto Bobbio, este trabalho teve por foco dois temas específicos: a defesa dos direitos humanos e a Teoria do Direito. Apresentadas as duas concepções, algumas conclusões puderam ser extraídas, tendo em vista o aspecto jurídico.

No desenho de uma Teoria dos Direitos Humanos, Bobbio já demonstra uma concepção positivista do Direito. Sua posição está assentada em três pilares. Em primeiro lugar, o problema atual dos direitos humanos é a efetivação. Na sequência, a questão da fundamentação - de difícil solução - foi resolvida com a ampla adesão à Declaração Universal dos Direitos Humanos. Em terceiro lugar, o consenso geral entre os Estados assegura a juridicidade desses direitos e a consequente necessidade de concretização.

Por outro lado, a Teoria do Direito defendida por Bobbio em diversas obras está pautada no formalismo positivista. A partir de uma visão de que os valores são subjetivos, o seu ideal de objetividade está centrado no conceito de poder soberano. A sua teoria tem a característica de não tratar a norma isoladamente, mas principalmente a partir da relação entre as normas. Assim sendo, a soberania caracteriza o ordenamento e as normas que integram esse ordenamento são as normas jurídicas - independentemente do seu conteúdo.

A crise consequente dessas duas visões é clara, pois não haveria nada de substancial que caracterizasse os direitos humanos. Em vez de serem os pilares dos Estados modernos, esses direitos foram reduzidos a ideais quase utópicos de luta contra a opressão. As garantias oferecidas 
por eles não são propriamente jurídicas, e sim políticas. Tudo por rejeição a uma dimensão valorativa no Direito. Essa rejeição aos valores - fruto da tentativa de tratar as Ciências Sociais da mesma forma que as Ciências Naturais - foi demonstrando a insuficiência do Positivismo. A formalidade não conseguia assegurar uma unidade substancial ao sistema jurídico.

Por isso, muitos autores que não necessariamente defendiam a lei natural, levantaram-se contra essa visão de Bobbio. Canaris (2002, p. 66) procurou reintroduzir a questão do conteúdo a partir de conceitos como adequação valorativa e unidade material do sistema. Larenz (1997, p. 674) utilizou os princípios para dar sentido ao sistema jurídico. Alexy (2004, p. 169) e Dworkin (2000, p. 175) fazem isso por meio da argumentação jurídica e na busca por uma resposta certa.

Por óbvio, os autores não partem do mesmo ponto e não têm os mesmos argumentos, entretanto em alguma medida sua busca é a mesma, pela superação da adstrição do Direito à formalidade da decisão do legislador estatal, como forma de superar exatamente o problema identificado em Bobbio - que limitou os direitos humanos à positivação pelos Estados ou pela comunidade internacional.

Na verdade, a convicção de Bobbio no sucesso dos direitos humanos pela via da positivação decorre da sua crença em um progresso constante da sociedade, no entanto, como deixa claro Douzinas (2009, p. 20), "o registro das violações dos direitos humanos desde as suas alardeadas declarações ao final do século XVIII é estarrecedor”. Os avanços científicos parecem ter, na realidade, intensificado as violações - e não a proteção - aos direitos humanos, principalmente desde as declarações de direitos da modernidade.

Uma nova discussão precisa ser feita a partir dessa percepção: Qual a finalidade da positivação dos direitos humanos? Considerando essas constatações e esse paradoxo, talvez seja o momento de reanalisarmos o discurso dos direitos humanos. Isto é, se essa positivação nacional e 
internacional não tem significado, em realidade, a apropriação pelo Estado de um discurso que agora não é mais questionador, e sim legitimador de sua atuação. Como Douzinas (2009), devemos perguntar: Qual o fim (a finalidade) dos direitos humanos?

Por todo o exposto, a visão positivista de direitos humanos dada por Bobbio pode ser aceita plenamente como uma defesa política. $\mathrm{O}$ pensamento positivista clássico defendido em suas obras, no entanto, se aceito juridicamente, acaba por anular todas as conquistas que as declarações internacionais objetivaram apenas cristalizar - e não criar. E, talvez, instaurando um processo muito mais prejudicial que benéfico.

\section{REFERÊNCIAS}

ALEXY, R. El concepto y la validez del derecho. 2. ed. Barcelona: Gedisa, 2004. BOBBIO, N. Teoria da norma jurídica. Bauru: Edipro, 2001 [1958].

. Teoria do ordenamento jurídico. 6. ed. Brasília: Editora Universidade de Brasília, 1995b [1960].

. O positivismo jurídico: lições de filosofia do direito. São Paulo: Ícone, 1995a [1961].

. A era dos Direitos. Rio de Janeiro: Elsevier, 2004 [1989].

. Elogio da serenidade e outros escritos morais. São Paulo: Editora Unesp, 2002 [1994].

CANARIS, C. Pensamento sistemático e conceito de sistema na ciência do direito. 3. ed. Lisboa: Fundação Calouste Gulbenkian, 2002.

DOUZINAS, C. O Fim dos Direitos Humanos. São Leopoldo: Editora Unisinos, 2009.

DWORKIN, R. Uma questão de princípio. São Paulo: Martins Fontes, 2000.

HART, H. L. A. O conceito de direito. São Paulo: Editora WMF Martins Fontes, 2009. 
KANT, I. A paz perpétua e outros opúsculos. Lisboa: Edições 70, 2002.

KELSEN, H. Teoria pura do direito. 8. ed. São Paulo: Editora WMF Martins Fontes, 2009.

LARENZ, K. Metodologia da ciência do direito. 3. ed. Lisboa: Fundação Calouste Gulbenkian, 1997.

MARITAIN, J. O homem e o estado. 4. ed. Rio de Janeiro: Agir, 1966.

MILL, J. S. Sobre a liberdade. Rio de Janeiro: Nova Fronteira, 2011.

NINO, C. S. Ética e Direitos Humanos. São Leopoldo: Editora Unisinos, 2011.

RAWLS, J. Uma teoria da justiça. 3. ed. São Paulo: Martins Fontes, 2008.

ROBLES, G. Os Direitos fundamentais e a ética na sociedade atual. Barueri: Manole, 2005.

STRAUSS, L. Direito natural e história. São Paulo: Editora WMF Martins Fontes, 2014.

Recebido em: $1^{\circ} / 10 / 2015$

Revisões requeridas em: 26/4/2016

Aceito em: 16/5/2016 